\title{
SMELL, ODOR, AND SOMATIC WORK: \\ SENSE-MAKING AND SENSORY MANAGEMENT
}

\section{Dennis D. Waskul, Minnesota State University Mankato \\ Phillip Vannini, Royal Roads University}

\begin{abstract}
Sensation (noun) is emergent in joint acts of sensing (verb). To sense, in other words, is to make sense, and sense making entails what we call "somatic work." We investigate these dynamics in the context of olfaction, highlighting how olfaction intersects with social, cultural, and moral order — thus compelling reflexive forms of somatic work by which people manage smell (as an act) and odor (as a sign). Our data are drawn from a convenience sample of twenty-three participants who reflected on their olfactory experiences through the use of research journals. We focus on three central dynamics: participants' attribution of meaning to odors, the somatic rules that structure perception, and olfactory facework. The participants in this study attribute meaning to odor through odiferous indexes that intersect with an individual's somatic career; olfactory somatic rules entail disciplined somatic work in relation to the intensity of odor, its context, and moral/aesthetic character; because odor conveys meaning it is part of the ritualized facework of everyday life. Odor is a subtle but significant component of the culturally normative and aesthetic rituals of expressive and impressive everyday life.
\end{abstract}


Flesh and organs bestow the capacity to sense, but they are merely the raw materials by which somatic perception is wrought. The act of perception requires the reflexive faculty to feel or perceive. Central to the very nature of the act (Mead 1938) and to the processes of making sense of the world (Dewey 1934; Peirce 1931) somatic perception is a reflexive expression of sociality —a fundamental basis for a sensuous understanding of the social world (Stoller 1989, 1997) and for the "possibility of a discipline of 'sociosomatics"' (Berger and Luckmann 1966:208)—a dynamic in which carnal sensations "become objects to ourselves" (Mead 1938:429). Sensations are "both a reaching out to the world and a source of information and an understanding of that world so gathered" (Rodaway 1994:5).

In this study we explore reflexive dimensions of somatic perception from an eclectic symbolic interactionist approach which views both the perceptive self and the signs of its perception as semiotic processes (Halton 1986; Wiley 1994). We pay attention not only to significant symbols, but also other important and much under-analyzed semiotic resources like indexes (see RochbergHalton 1982). We argue that sensation (noun) is emergent in joint acts of sensing (verb). To sense, in other words, is to make sense, and sense making entails what we call "somatic work." We investigate these dynamics in the context of olfaction, and seek to contribute to sociological literatures on sensual perception $^{1}$ (also see Fine 1995) We highlight how olfaction intersects with social, cultural, and moral order thus compelling reflexive forms of somatic work by which people manage smell (as an act) and odor (as signs). We focus on three central dynamics: participants' attribution of meaning to odors, the somatic rules that structure perception, and olfactory facework.

\section{SENSE-MAKING AS SOMATIC WORK}

"[S]ensation is the result of the activity of the psycho-physical organism, and is produced, not received...Sensation expresses the excitation, the stimulation of mind. 
It arouses the mind to put forth effort..." (Dewey 1967[1887]:43-4, emphasis in original).

Smell is an act (verb); it is something that people do. In contrast, odor is a state (noun); it is an olfactory condition. Odor is also a sign, and in Peircean terms it is a sign-process: a percept which compels interpretive work. The smelling of odor evokes olfactory definitions of the situation by which multiple meanings mediate between the act of smelling and the condition of odor. In this way, odor and smell are conjoined in an interpretive relationship: the objective conditions of odor and the potential for inherent meaning (cf. Halton 2004) it carries are inter-subjectively perceived and inseparably bound in the act of smell by use of semiotic resources. Such is olfactory sense-making: the first fundamental component of the processes of socio-somatic perception we refer to as somatic work.

Inspired by popular sociological concepts such as identity work (Snow and Anderson 1987) and emotional labor (Hochschild 1983), somatic work refers to a diverse range of reflexive symbolic, iconic, and indexical sense-making experiences and practical activities. Through such experiences and activities individuals produce, extinguish, manage, reproduce, negotiate, interrupt, and/or communicate somatic sensations in order to make them congruent with personal, interpersonal, and/or cultural notions of moral, aesthetic, or and/or logical desirability. Somatic work is arguably an original moniker; however, its origin lies deep in the history of interactionist, constructionist, and pragmatist thought. For example, Becker's (1963) study of marijuana users suggests that the "taste" required for perceiving and interpreting the effects of marijuana is mediated by reflexive processes. Sensing is a social practice_-rather than purely chemical or physiological—since reflexive work is required for marijuana users to cultivate a nuanced sense of otherwise "vague impulses and desires," a sense of how that experience may be interpreted, and what it means (Becker 1963:42; Becker 1967). Just as the sensory experience of marijuana use "is a function of the individual's conception 
of marijuana and of the uses to which it can be put" (Becker 1963:42), so too is any other somatic perception. Somatic perception hinges on work that is reflexive, situated, pragmatic, phenomenological, and emergent from dialectic body techniques (Mauss 1973 [1934]) where meanings emerge at the intersection of the perceiver's somatic career and existing social habits of uses of the senses (see Dewey 2002 [1922]; Simmel 1997 [1907]).

In the case of olfaction, we can understand somatic work as a process of attribution of meaning to odoriferous symbols and indexes. . Indexes, according to Peirce (1931), are signs that denote meanings from the alleged presence of natural causal processes. For example lightning is indexical of a storm; smoke is indexical of fire, and so forth. In Anglophone North American culture the meanings of odors are fashioned through indexical relations in most mundane situations: the perception of an odor-generally a strong one, or perhaps one that is seemingly out of context—alerts us to reflect about its plausible sources: the odor of burning grease may alert us to tend to the bacon burning in the pan; the odor of burning metal in our automobile cues us to reflect on the working condition of our brakes, and so forth.

Meanings, even when indexical, are neither uniform nor universal. In Peircean semiotics the relationship between an object and the sign which expresses it is always mediated by an interpretant, that is, by the sense that is made of that relationship. That sense is both perceptual and symbolic. An index compels meaning: whatever compulsive element is being perceived is indexical, but the interpretive work enacted is symbolic. So, even though indexes carry an obvious potential of inherent meaning, one has to do at least a bit of interpretive work to make meaning, and especially connotative meaning, to make sense of sensations. At its simplest and most basic level, somatic work is thus a concept that describes how people hermeneutically make sense of perceptions and how they attribute meaning to them. As we will soon see, however, this somatic work is multidimensional. 


\section{SOMATIC RULES: MORAL ORDER AND MORAL ODOR}

Somatic work is fashioned in the context of negotiated somatic rules that vary by personal, interpersonal, situational, contextual, cultural, and historical circumstances. Somatic rules inform not only sense-making but also the impressive and expressive dimensions of somatic work that are routinely displayed in everyday social conduct. Thus, somatic work implicates aesthetic and moral dimensions of sense-making and impression management.

Few social norms are clearer than those which stipulate against foul odors (see Tuzin 2006). As Corbin (1986) has pointed out, rules against the excessive presence of odors have been strictly and invariantly enforced throughout successive historical waves of the sanitization movement. Understood as a force of civilization of manners (Elias 2000), and a corrective response to what Drobnick (2006) calls odorphobia, somatic impression management stands as one of the most culturally unique strategies of normative behavior, of which olfaction plays an especially significant role. Indeed, olfactory somatic rules are largely legitimized by discourses of "health" and “cleanliness" (Largey and Watson 1972)_discourses that, among many things, equate cleanliness with godliness and that which is healthy and clean with a pleasant smell; a cultural motif frequently exploited by the advertising industry. For example, "laundry not only has to be clean, but it has to smell clean” (Synnott 1993:193, emphasis in original).

As stated by Largey and Watson (1972:1022) "particular odors, whether real or alleged, are sometimes used as indicants of the moral purity of particular individuals and groups within the social order, the consequences of which are indeed real." The bitter stench of stigma clearly reveals moral judgment (see Tuzin 2006). During the middle ages it was believed that sorcerers and heretics could be detected by their foul odor (Summers 1956:44). In medieval Europe one of the most widely accepted theories of causes of the plague was the pathogenic odor of putrefaction (Classen, Howes, and Synnott 1994). Even Martin Luther agreed: contagion "poisoned the air or otherwise infected 
the poor people by their breath and injected the moral poison into their bodies" (quoted in Norton 1975: 20). Just as "evil stinks" (Synnott 1993: 191), the aroma of sanctity is pleasing. In Exodus (30:22-4) the Lord gave Moses a formula and instructions to create perfume. In the New Testament Jesus was anointed with perfume from an alabaster vase-a treatment suitable for the most worldly great and, according to Matthew (26:6-13), much appreciated by at least this living deity.

The fundamentally public nature of odor partly explains why olfaction so directly intersects with morality and moral discourse (and, as we will soon see, impression management as well). In direct opposition to the fundamentally private nature of taste (see Fine 1995), odor is shared by all within olfactory sensual proximity. For this reason Dewey (1967[1887]:222) deemed taste the most "personal in the narrowest of sense" and smell more communal due to its "objective and universal" quality:

It must be noticed that the organic sensations and taste are personal in the narrowest of sense... a substance must be actually taken into the organism though the mouth before it can be tasted. Such feelings tend to divide one individual from another, for their enjoyment by one is either not shared with another, or is actually incompatible with such sharing. In smell, feeling becomes a whit more objective and universal. The odorous object, as a whole, is not dissolved in the organism. A number may get and enjoy similar feelings from one object.

In short, olfaction is a rich arena for sociological investigation, especially in terms of morality, because odor is fundamentally public and shared. Like dust (Fine and Hallett 2003:12), odor "once recognized, becomes a cultural marker and is used to create social order... [olfaction] is not simply something that happens. It is something with which groups must deal. As groups deal with [odor], they reproduce the larger cultures in which they are embedded, they demonstrate processes of 
contention and control, and they negotiate meanings through similar processes that occur in larger units" (Fine and Hallett 2003:12).

Because olfaction and odor are constructions of normative aesthetic and moral code, olfactory rules are enforced and odor is faithfully managed. The management of odor is common and widespread, observable in almost every-body, every where. In Anglophone North-America odor is traditionally something to be eliminated or produced—on (and in) the body, the home, at work, automobiles, our communities; by use of air fresheners, deodorants, breath mints, fans, ventilation, air purification systems, pollution laws. Even the mere mention of odors in conversation, especially body odors, is a delicate subject and thus it is not uncommon to find ourselves occasionally ignoring or denying the presence of uncontrollable, bad odors out of both a sense of tactfulness and taboo (cf. Zerubavel 2006). Adherence to the olfaction rules of moral odor/moral order represent more than the folkways of a culture and more than a matter of manners, politeness, and etiquette. Indeed, as testified by recent "scent free" work and public space regulations, violations of olfaction rules are of potential legal concern and the production of inappropriate odor can be cause for civil litigation (although, given its gases consequences, one might wonder if the same logic might result in a bean prohibition—at least for human consumption, and possibly our companion animals).

More than merely "giving off' a creditable odor, olfactory impression management is built of two basic processes identified by Largey and Watson (1972:1024-1032): odor-avoidance and odor-attraction. Odor avoidance refers to cultural inclinations to avoid individuals, groups, or environments that are considered foul smelling; odor-attraction refers to cultural tendencies to approve of individuals, groups, or environments that are considered aromatically pleasing (Largey and Watson 1972). These basic cultural olfactory processes are expressed in deodorizing ritualsculturally grounded practices that entail "the removal of socially discreditable odors through such activities as washing, gargling, and cleansing of teeth" (Largey and Watson 1972:1027), and odorizing 
rituals - practices that involve the "presentation of self with accreditable odors through the 'art' of perfuming” (Largey and Watson 1972:1027). By means of deodorizing and odorizing rituals people attempt "to avoid moral stigmatization and present an olfactory identity that will be in accord with social expectations, in turn, gaining moral accreditation: he who smells good is good" (Largey and Watson 1972:1028). However, as we will soon illustrate, deodorizing and odorizing rituals intersect with positive and negative interpersonal rituals (Durkheim 1915, Goffman 1971:63) that either "affirm and support the social relationship" between odors and their source or evoke the “individual's right to private 'preserves' and 'to be let alone”" (Cahill 1985:39).

\section{METHODS AND DATA}

We collected data through the use of research journals (Alaszewski 2006). We asked two cohorts of graduate students enrolled in an applied communication program at a Royal Roads University to record their experiences with smell over a period of two weeks. We approached the students with an email explaining our interest in the role of non-verbal communication and solicited volunteers to participate. We did not promise extra credit or other incentives. Those who volunteered were provided with instructions and the research journal via email as an electronic file. We also invited the students to solicit the participation of acquaintances of theirs whom they thought might be interested in the study. We guaranteed anonymity by creating a research email account, which participants could use to send us their completed journals in the form of electronic files included as email attachments. A total of twenty-three journals were completed, fifteen by women and eight by men. Ages ranged from twenty-four to fifty-nine, with a mean of almost thirty-eight years of age. The sample was ethnically diverse, including fifteen Caucasians, two East Indians, two East Asians, two South Americans, one Mid-Easterner, and one African.

The journals contained questions that asked participants to describe their favorite and least favorite odors, to identify memories associated with odors, to document daily body-odor 
management efforts, to describe moments when during the course of daily life they became explicitly aware of smell, and to disclose and describe a situation in which they felt they smelled bad. In response to seven questions respondents answered with as little as 181 words and as much as 1,303. Average response was just under 700 words (roughly two and one-half pages of doublespaced typed text).

Sensations of smell, like sensations of taste, are not easy to express (Fine 1995) and for this reason we felt that the use of the written word, and the reflective possibilities that writing provides, would help our research endeavors. Whereas the collection of data via the use of research journals offers the researcher no opportunity to observe interaction, it offers a wealth of reflective, thoughtout, richly descriptive self-reported verbal data that allows the researcher to focus on the semiotic and linguistic components of olfactory experiences. Our analysis of the data follows the analytical procedure of socio-semiotic ethnography (Vannini 2007). Briefly, organization and analysis of data from this perspective entails a process of making an inventory of semiotic resources, considering their potential meanings and categorizing their multiple forms of employment in concrete social situations, identifying the rules for their use, outlining their polysemic potential, and interpreting the cultural and historical significance of the frames which inform social agents' meaning-attribution, paying special attention to the multidimensionality of meaning and the role of semiotic resources in shaping the power dynamics of interpersonal relationships.

We have divided our data analysis into two main sections. In the first, we describe how participants make sense of odors, the fundamental dynamics of this somatic work, and discuss two of its major components: habits of sensing and somatic escalation. In the second, we describe somatic work as olfactory impression management by focusing on facework and olfactory stigma. 


\section{MAKING SENSE OF ODORS}

By active and reflexive sense-making participants of this study indicated, with seemingly great ease, what odors denoted and connoted. This deceptively simple act of indication is based on a process of negotiation of multiple semiotic resources; resources such as individual and collective memories, habits, common associations, moral and aesthetic codes, the qualitative immediacy of odors, and more. These processes illustrate how perception is hardly a physiological event alone: sensation does not exist prior to experience but flows from it; "sensation... is produced, not received" (Dewey 1967[1887]:43). In order to understand these processes we begin by clarifying the conceptual distinction between denotation and connotation. We then explain how the particulars of an individual's somatic career inform his and her somatic work.

Because vocabularies of olfactory qualities are scarce in English, derive mostly from other sensations (like touch and taste; e.g. odors may be regarded as "strong" or "weak", "sweet" or “sour," etc.) and are tautological (e.g. "coffee smells like coffee” [Synnott 1993:184]), indications of odors are denotative and connotative in rather rudimentary forms rather than richly descriptive unto themselves. For example, when asked to identify and describe her favorite aromas Michelle (age 30) wrote: "I love the smell of fresh baked cookies because it reminds me of coming home from school when I was a child to fresh baked cookies.” As Michelle suggests, the odor of fresh baked cookies indicates_-or in other words denotes—-the presence of fresh baked cookies.

This is how odors are most often interpreted by our participants and arguably all of us alike: by immediately and confidently identifying their first-order meaning, their alleged present source, and by doing so within a defined context. Such contextual association is especially important in situations in which we sense that something is right or good and yet we are hardly able to verbalize why or how this is so (Fine 1995). Denotation appears to be uncomplicated and common sense, yet denotation is, in fact, an interpretation - a hermeneutic relationship based on a situated association 
between an object and a signifying medium which expresses said object. In Michelle's case, and in many other mundane cases, the associative relationship between odor and its source also generates an evaluative interpretation: Michelle loves the odor of fresh baked cookies, and that loving sensation is her sense, her evaluation of that odor. In this case we can refer to that loving sensation, that second-order evaluative meaning, as a connotation.

A connotation is also based on an association, but in this case the association is on a higher scale of abstraction. While denoted objects, like freshly baked cookies, are immediately present within the circumstances of perception, Michelle's memories of coming-home from school are not present in the same fashion. In short, the smell of freshly baked cookies connotes not a universal sensation but a particular sign for Michelle, a sign grounded in her biography: a mental image of coming home from school when she was a child and an unspecified sense of nostalgia for those times. "Previous experiences"—rightly notes Fine (1995:256)— “provide the basis for comparative judgment" and for evaluation. Like Michelle's sense-making, each of the following suggests the intersection of previous experiences and biographical elements in the connotative dimensions of olfactory somatic work:

[My favorite smell is] vanilla. It is the smell of baking and growing up my mom baked lots. The house smelled great and it was a sure sign we got a snack out of it. (Jackie, 36)

[My favorite smell] is freshly-ground coffee, simply because it smells so good. I also have happy associations of the coffee shop I worked at for many years before and during my undergrad studies. Also, both my parents are huge coffee drinkers and I always got to push down the bodum filter as a kid. Coffee has always been a big part of our family life, I guess. So it's a good smell with positive associations all around. (Kate, 29) 
As these examples illustrate, olfaction is commonly marked by what we call somatic work: a process whereby a somatic perception undergoes a reflexive interpretation. Such interpretation is marked by activities such as active reminiscing, forming chains of associations, evaluating, interpreting the significance of unique biographical particulars and/or social norms, and attributing meanings. Thus somatic work yields evaluations that fall in line with interpersonal and/or normative expectations. Consider, for example, the somatic work that accounts for Kate's (age 29, ellipses in original) dislike of the smell of baby power:

I despise the smell of baby powder. I went out with a guy who put it down his pants and to this day it makes me a bit sick. We went out for a couple of years and he was pretty tortured, negative, smoked too much pot, wanted to live in a cabin away from all people-he hated people for some reason. We had some kind of crazy chemistry and I did love him, but that part is hard to remember. He would wear jeans that were waaay [sic] too baggy, weighed down with a big belt, wallet chain, and smelling like baby powder mixed with pot and cigarettes. That is my strongest memory of him... maybe it was that the smell permeated the air of a relationship that was thoroughly bad for me. It makes me shudder when I think of it.

Kate's narrative shows she uses multiple and diverse semiotic resources to make sense of her perceptions. This employment of semiotic resources is what we refer to as the sense-making component of somatic work; a type of negotiating activity that constitutes work even in the absence of highly expressive language. For example, in the excerpt below Frank (age 45) described one of his favorite odors_-vividly evaluating the sense that he makes of it—all of this without describing its essence:

One of my favorite smells is that of fresh baked bread. It reminds me of many things including my grandmother, my mother, my brother and I making numerous loaves to get 
ready for winter in Alberta. It has associated with it thoughts of a warm kitchen, important people in my life.

As Synnott (1993:187) has argued, “odour, memory and meaning are...intimately linked and reach deep into our personal lives, all day, every day." We can conceptualize these intimate links as part and parcel to a somatic career. Somatic careers can be individual and collective, since both individual collective memories as well as idiosyncratic or common habits can be brought to bear into the sense-making acts of individuals and groups. A somatic career is the historical dimension of somatic work: a living history of the somatic self and of the social organization of the labor of perception, as well as a received orientation to future somatic work. Somatic careers are built of habits of sensing.

Habits of Sensing

Our data analysis shows that, rather than elaborating on the essential qualities of the odors themselves alone, participants were more likely to distinguish between enjoyable and disagreeable odors in terms of the habits of sensing that olfaction evokes. For example, Frank's sense-making reported above is informed by meaningful biographical resources—-family memories that date back to his childhood in Alberta—which bear on his olfactory evaluation. These "involuntary memories" (cf. Proust 2001) are semiotic resources that inform his interpretation. We refer to these biographical resources as habits of sensing, i.e. sense-making patterns that express, articulate, and are the result of individual and collective sensorial biographies and histories.

By taking into account an individual or a group's somatic career ${ }^{2}$ it is easy to understand the evaluative outcomes of perception. Consider, for example, Ashley's (age 48) account in the excerpt below; even the occasionally questionable smell of Lake Ontario (and lake water in general) gives rise to positive evaluations that are understandable by virtue of her reported nostalgic feelings: 
[I enjoy of the smell of] The shore of a fresh water lake! Because I grew up close to Lake Ontario (long enough ago that it smelled ok most days). I went down to the lake in all stages of my life. With my family as a young child, with my friends when we went off on our bikes, as a teenager for quiet, and as a young adult on runs and refuge ... to look out over the water, listen and breathe. It all goes together under the smell.

Nostalgia shapes the meaning of odor by dwelling at the core of individual biography and "at the very heart of a generation's identity" (Davis 1979:111). Nostalgia is a form of attachment to habits, in this case habits of perception, which play a powerful role in sense-making. Indeed, as each of the following illustrate, nostalgia informs the interpretive act as a cluster of habits and perspectives; as a form of sentimental selective attention (James 1983 [1890]; Mead 1938) toward certain characters of the sensory field—an attention "which answers both to [the perceiver's] immediate sensitivities and to his [sic] experience" (Mead 1938:7).

I remember a kid's book called Pat the Bunny which has different textures for kids to touch; daddy's rough beard (sandpaper), a shiny mirror, etc. At the end, you got to pat the bunny's belly, which was soft cottony fur and has a very unique smell. I bought the book again several years ago when a friend had a baby and found that it still smells the same —a little bit like baby soap or something, but very distinct. It brings me right back to my childhood. I think it's a combination of a nice, clean, fragrance combined with happy childhood memories (I loved that book and remember reading it with unidentifiable but very nice adults) that makes it so special (Kate, 29).

One of the most pleasurable odors I recall is from my childhood - it was during the fall in Edmonton when my parents would make mustard pickle. This would take an entire weekend and involved the chopping and cutting of cauliflower, peppers, 
onions, etc. and the very strong scent of vinegar and mustard would take over our house. It was a happy memory of my parents together in the kitchen, engaging in a ritualistic activity as the coziness of fall and autumn surrounded us (Rose, 39). Indeed, "all perception involves an immediate sensuous stimulation and an attitude toward this stimulation, which is that of the reaction of the individual to the stimulation" (Mead 1938:3). This evaluative attitude—which Mead called "impulse" — is the result of "some imagery which is taken from past experiences in which the responses have been carried out" (1938:3).

In simpler terms Dewey used the word "habit" to refer to the bodily rootedness of impulse. “Habits are acquired” functions—wrote Dewey (2002 [1922]:14)—which manifest "skill of sensory and motor organs, cunning or craft, and objective materials. They assimilate objective energies, and eventuate in command of environment" (Dewey 2002 [1922]:15). Habits are not synonymous with sensing, yet for Dewey (2002 [1922]:32) it is "habitual attitudes which govern concrete sensory materials." Thus we intend our concept of habits of sensing as "filters [of] all the material that reaches our perception and thought." It is precisely these habits of sensing that account for Peter's (age 57) attachment to the scent of face powder; his habituation with the fragrance his grandmother used to exude and as wistful disposition toward earlier times:

My mother's mother, my Nana, used a face powder. She was a poor widow-lady so her choice of product was probably the cheapest available in Moncton New Brunswick in the 1950s. But it was her smell. Throughout my life I've had fleeting sniffs, usually of old ladies, that take me back like Proust's Madeleine, to being 5 years old and meeting my Nana at the bus station after her shift at the airplane engine factory (she was a "Rosie the Riveter" who wasn't laid off after WW2). Her unfailing gift of a stick of Juicy Fruit gum was the highlight of my day. It was pure unadulterated pleasure to be hugged and kissed by my powdery Nana. 
As we have illustrated, participants told of nostalgic feelings for moments in time-they also expressed nostalgic feelings for special places, which are often informed by feelings of “displacement" or the "involuntary disruption of place attachment” (Milligan 2003:381). As Milligan (2003) argued, displacement from a beloved place is marked by discontinuity in one's biographical identity and in this fashion "nostalgia provides one way of maintaining or regaining identity continuity" (Milligan 2003:380). Examples of this relation have been noted by researchers of smell (e.g. Hirsch 2006) and also abound in our data. For example, Susan (age 25, ellipses in original) identifies her liking of the smell of Coppertone sun block lotion with vacationing in Spain:

This is such a funny thing to have as a favourite smell, but I just love it. I used to say that if I could find it in a perfume I would wear it everyday! When I was little, my family used to go to Spain for vacations. Every year we would pack up and ship out for three weeks. This was the only time when I actually saw my father, as he was often away half the year traveling for work (and the other half he spent at the office) so I associate a sense of wellbeing and peace with that smell. It was great to be so carefree-no school, no chores...nothing to do but swim and run around in the sun! I smell it sometimes on other people, usually in the summer, and I get immediately transported to the beach. I feel warm, I can hear the waves...it's quite the experience!

Similarly, Allison (age 32) is delighted by the smell of jasmine because it evokes blissful memories of her experiences in Thailand:

The most pleasurable odor I recall is the smell of jasmine flowers opening on a warm evening. On a trip back to Bangkok from Changmai, Thailand I remember sitting on the train car surrounded by my backpack and all my personal possessions. I had spent the morning at the market shopping for food items for a Thai cooking class that I was taking. My instructor bought each of her students a necklace of jasmine flowers at the market that 
were tightly closed. It wasn't until the warmth of the day had taken effect and the flowers began to open on the evening train trip that I noticed that I still had the necklace on. The smell was wonderfully sweet and musty and encompassed all the good things I had experienced in Thailand. I rarely smell the same smell anymore but when I do it reminds me of my independence traveling alone in foreign lands and the beauty of Thailand.

On the other hand, even an odor generally deemed pleasant or neutral can be interpreted as noxious when linked to negative memories. Consider, for example, Beth's (age 31) "gag reflex" at the smell of the fabric stain-remover Spray and Wash:

Right now I would say [I dislike the smell of] "Spray and Wash" because I recently had a very bad and sickly night that involved imbibing large quantities of red wine. By "accident", I spilled a glass of red wine on the white carpet in the office of my parent's house. They were away on vacation at the time and so I drunkenly panicked tried my best to clean it up. I didn't know where they kept their carpet cleaner, so instead I used "Spray and Wash", the stain remover for clothing. I used half the bottle on the stain. I reasoned at the time that more was better and the more it soaked into the carpet the more the stain would magically disappear. To make a long story short, my brain has linked the two smells (red wine \& Spray and Wash), and my sickly drunken state together to create an instant gag reflex at the smell of "Spray and Wash.”

Beth's evaluation of Spray and Wash has nothing to do with the essential qualities of the odor itself — it can only be understood in light of her unique somatic career, that is, in light of a sensorial reservoir of "memories that contains versatile, resourceful interpretive models and cultural schemes" (Rapoport et. al. 2002:176). This is not to suggest that all odors are associated with biographical particulars or that odors' essential qualities are inconsequential. Rather, we suggest that perceptions 
associated with "symbolic images and allusions from the past... by virtue of their resource in a particular person's biography tend to be more idiosyncratic, individualized, and particularistic in their reference" (Davis 1979:222) and thus tend to matter greatly within individual acts of perception. Habits shape sense-making by functioning as interpretive resources rooted in past sensation and conduct, but at the same time in the very course of their operation in the process of perception habits have the potential of adding "new qualities and rearrang[ing] what is received" (Dewey 2002 [1922]:32). This aspect of the process is magnified in the case of somatic escalation, the second component of somatic career.

Somatic Escalation and Somatic Rules

We have argued that denotation and connotation are clearly distinct: odiferous denotation indicates immediately present material source(s) and connotation refers to an evaluative abstraction. In actuality, in many cases, the line between denotation and connotation is less concrete and far more entangled. Often there is a fusing and escalation of olfactory sense-making. Indeed, by somatic escalation we refer to cases in which denotation and connotation become fused into immediate evaluative perception — a process that highlights how normative moral and aesthetic discourses inform immediate perception. Consider, for example, Ashley's (age 48) statement:

I think smell immediately communicates to guests if a home is hygienic, or well cared for, and consequently, if the family cares well for itself. Civilized I suppose. Status. A foul smelling home is totally low class_-same with an individual. The consequences of not paying attention to odors in the home could be hygienic/illness and stigma. For Ashley certain odors "immediately" connote hygiene (or lack thereof). Hygiene is associated with care for the self and others, class, status, health, and civilization. Ashley is not alone in these sentiments. For example, linking bad smell of her children with the code of motherly labor of love, Karla (age 32) writes: 
[My least favorite smell is] the smell of my children when I tuck them in at night and they should have had a bath—-the way their hair smells—it makes me feel as though I have neglected my motherly duties.

Ashley (age 48) echoes Karla's sentiments by linking the odor of feces with a call to motherly duty to keep up with hygienic control of the house and children:

[My least favorite is the smell of] poo. For a while there my daughter was in diapers, I had two cats with their litter tray, and was house training a very large (45 lb) puppy. I got terribly tired of looking after their potty habits! It was also worrisome that if things got the slightest bit ahead of me, the house would smell, or my daughter might get some on her hands. Hygiene and self-respect go together.

Perception is often associated with cultural values (Fine 1995; Zerubavel 1997). As Fine (1995:246) writes, "sensory judgments are grounded in social relationships, face-to-face negotiations, social structures, and organizations." These are value judgments that have seemingly "immediate" and potent somatic significance: odor is perceived, with great ease, as essentially bad, foul, ill, thus conflating what emanates a particular odor with how that object smells. It is, indeed, common sense-an expression that refers to a widely shared way of making sense of sensory perceptions-to suggest that a certain olfactory condition has seemingly "natural" or "essential" qualities which make it good or bad or even uncivilized, sick, and low in social status. Yet—regardless of the prevailing beliefs that these immediate associations are "natural"- they are inevitably learned (Herz 2006), and thus cultural, even ideological. Thus are the conditions of somatic escalation-conditions in which the denotation and connotation of an odor are blurred into one immediate "common-sense perception," so that an odor immediately and simultaneously both denotes and connotes an abstract evaluative concept (like civilized hygiene or status). 
The perception of indexes has a strong tendency to incur into somatic escalation. Peirce's explanation is particularly enlightening: an index is a "genuine relation" (Peirce 1931::2.92) between an object and its expression and that this connection is seemingly "matter of fact" (1931:4.447), “real” (1931:5.75) “direct[ly] physical” (1931:1.372), “unequivocal” (1931:4.531), and working effectively by "blind compulsion" (1931:2.306). Indexes seemingly cannot lie. Or perhaps, they are simply ideal for naturalizing cultural dynamics. Consider Mary’s (age 59) “common sense" statement below:

I associate smelling good in a personal, bodily sense, with being clean, with good personal hygiene. Not smelling good is a big turn-off, not only sexually, but in every other way.

Mary's cultural association of body odors with cleanliness, sexual desirability, and overall personal appeal naturalizes a perception by making it seem "common sense." Mary's statement is a typical example of a somatic escalation: body odor (in this case) is immediately subjected to an aesthetic and moral evaluation; if the body smells good then it "naturally" connotes a sense of cleanliness, health and hygiene, sexual appeal, and overall sense of human worth and decency.

What odiferous indexes immediately denote is therefore not only their source, but also their normative moral and aesthetic value. In this case, as Barthes (1974:9) pointed out, "denotation is not the first meaning, but pretends to be so; under this illusion, it is ultimately no more than the last of the connotations (the one which seems both to establish and close the reading), the superior myth by which [the sign] pretends to return to the nature of language, to language as nature." A somatic escalation is, in sum, a process of naturalization: of turning multiple abstract interpretations, deeply entrenched within a culture and highly idiosyncratic, into an illusion that perception is natural and free of interpretive work; into an illusion that the object and the sense that is made of it are 
immediate, “common-sense," identical, and transparent. As Volosinov (1973:105) has rightly pointed out: "meaning is molded by evaluation... meaning is always permeated with value judgment."

The fact that some odors are judged "offensive" and others are deemed "pleasing" clearly implies a system of order that is bound by somatic rules that are normatively aesthetic and moral. Borrowing from Douglas (1970:48), we suggest that disagreeable odors are those that offend against order; they are "the by-product of a systematic ordering and classification of matter, in so far as ordering involves rejecting inappropriate elements." Offensive odors are those that deviate from olfactory somatic rules. Somatic escalation functions on the basis of somatic rules for sense-making. Somatic rules are contextual and diverse; their application is consistent but variable. Our data show the functioning of basic olfactory somatic rules disciplining somatic work in relation to variables such as the intensity of odor, its context, and its moral/aesthetic character.

The olfaction order of prevailing somatic rules entails a negotiated structure of intensity. Odor is sometimes perceived as too pungent or perhaps not fragrant enough. Several participants in this study wrote about the desire to be aromatic_-but also expressed concerns about overpowering scent. Nichole (age 40) wrote: "I like to wear a fragrance that is appealing, yet not overpowering." Kate (age 29) recollects her near faux pas — a close brush with olfactory intensity deviance-how a friend reminded her of the applicable somatic rule, and her prompt conformity: "I tried some perfume (from a sample my sister-in-law gave me) this evening before going out for dinner with a friend. She said it was too strong, so I washed it off." More than just a personal preference, for some participants in this study olfactory somatic rules of intensity are regulated and enforced by contemporary "fragrance free" mandates that demand olfactory political correctness:

In my field of work, and generally in public service, there has been a push toward scent free environments. So, aftershaves, cologne, and perfumes are not politically correct. There also 
seems to be a higher prevalence of environmental allergies. Those allergies can be debilitating. Finding a good deodorant without a scent is difficult (Frank, 45).

Olfaction order also concerns a negotiated structure of contexts: we are more or less sensitive to odor depending on whether we perceive the aroma as appropriate to the context. As Michelle (age 30) suggests, the smell of garlic may be appealing in a Caesar salad but, once consumed, the same aroma evoked a very different response in her friend's car:

There was a day (way back when) that I went to Earl's for lunch and had a Caesar salad. I was probably 17 or 18 years old. I enjoyed the salad at the time. It wasn't until I sat in an enclosed space (my friend's car) that I noticed that the smell of garlic was radiating from my pours. The garlic smell was even more apparent to me when my friend commented. I felt awful. We both agreed that stopping to get some gum or mints was a very good idea.

Even a normally disagreeable odor might be deemed pleasing when appropriately contextualized. As Miller (1997:247) suggests, distasteful odors can be made tolerable if the circumstances are appropriate: the smell of "strong cheese is much more tolerable than if thought to emanate from feces or rank feet." Likewise, Ashley (age 48) admits to enjoying the smell of her dog-“even though he smells rather awful" — and explains:

[I enjoy the smell of] My dog when we cuddle. Frankly even though he smells rather awful, the scent is associated with our "friendship". It smells like home, and oddly enough, peace.

Finally, olfaction order is also structured by somatic rules regarding assessments of moral/ aesthetic character. As previously suggested, many odors are immediately evaluated as positive or negative, good or bad and these evaluations are not neutral: what smells good is good, what smells bad is bad (Herz 2006; Synnott 1993). For example, Jackie (age 36) wrote: 
It is important to control or manipulate odour on your body when you will be in social situations so that you are not judged based on poor body odour. Strong or bad body odour could be taken as a sign of being unclean or sloppy.

Among the most morally and aesthetically offensive are odors that originate in the body, odiously upset public space, and assault the olfaction of others. As Simmel suggests, "that we can smell the atmosphere of somebody is the most intimate perception of him [or her]" —and some atmospheres are apparently too intimate, obliging "a selection and a taking of distance" (1907:658). Particularly offensive is the moral and aesthetic character of odors that originate and waft from either end of the digestive system: halitosis, vomit, flatulence, urine, and feces. There is a cultural expectation as to what belongs inside and outside the body and odors that violate these expectations are considered polluting or contaminating (Turner 2003, Weinberg and Williams 2005). Thus, for example, participants in this study were commonly concerned about bad breath:

I'm always slightly paranoid about having bad breath. If I don't have gum or haven't just brushed my teeth, I'm careful not to get too close to whomever I'm talking to, and assume that they any reaction/blink is them flinching at my halitosis. (Kate, 29)

Because fecal products are regarded as a "universal disgust substance" (Rozin, Haidt, and McCauley 1993:579) several participants in this study suggest flatulence and the smell of feces especially contaminate moral and aesthetic character:

As part of the long term effects of a broken back and fractured pelvis, my bowel functions can sometimes be impacted... literally! This can lead to flatulence. I find it most embarrassing to be at a work meeting or in a small event and to be experiencing this social challenge (Frank, 45 ellipses in original).

Allowing one's fecal smells to escape and assault the olfaction of others "suggests a momentary loss of control" (Goffman 1963a:69, also see Weinberg and Williams 2005). This kind of control—and 
guarding against its loss—clearly implicates the expressive and impressive dimensions of olfactory impression management. In short, somatic rules of intensity, context, and moral/aesthetic character intersect with the normative dramaturgies of everyday life and rituals of facework (Goffman 1967). “Aesthetic order"—as Fine (1995:266) has elegantly and succinctly put_-is “a domain of social order."

\section{SOMATIC WORK AS FACEWORK}

Odor is perceived and immediately evaluated in accord with basic olfactory rules. Individuals become sensitive to these rules throughout the process of socialization; a process that refers not only to technical learning but also to the "moral evaluation of objects and actions_-an evaluation that easily conflates with sensory judgments" (Fine 1995:266). Therefore, it is prudent to suggest that olfactory somatic rules are generally enforced and odor is dutifully managed in all instances of social interaction. As Peter (age 57) suggests, “There is a manipulative element to controlling odors." Indeed, odor conveys meaning and is, therefore, a significant element of the dramaturgies of everyday life. As we will illustrate olfactory impression management is often expressed in positive and negative interpersonal rituals, violations of which may be stigmatizing.

Olfactory Impression Management: Positive and Negative Interpersonal Rituals of Olfactory Face-Work

Goffman (1967:45) pointed out that "the general capacity to be bound by moral rules may well belong to the individual, but the particular set of rules which transforms him into a human being derives from requirements established in the ritual organization of social encounters (Goffman 1967:45). Likewise, constructions of odor, olfactory somatic rules, and perceptions of smell directly intersect with the normative dramaturgies of everyday life — as both a part of the processes of presentation of self and a means of bestowing sanctity or stigma unto others. In this way "the physical and the moral are united in odour" (Synnott 1993:191) and represents a genuine form of 
somatic surveillance, as evidenced by Nichole (age 40) who wrote "Personal body odor is something that I prefer to keep under control at all times, regardless of whether I am in public or not."

For these reasons, the participants in this study are "dramaturgically aware" (Brissett and Edgley 1990) of the significance of odor to impression management—and particularly in terms of the implications for "face" (Goffman 1967:5)—"the positive social value a person effectively claims...in terms of approved social attributes." "Smelling good is a sign of being good" (Synnott 1993:187)—which is clear to Rose (age 39) who wrote, "Just like looks smell is tied to impression; if you want to make a good one you need to smell nice." Likewise, Steve (age 56) who wrote "I think you can lose credibility with people if odor is not controlled." Several participants in this study expressed similar sentiments:

Anytime I expect to be in close proximity to others, like at a Doctor's appointment or church, are times that I pay particular attention to how I smell. (Allison, 32)

It is important for me to smell good when I am with other people. It makes me feel good about myself and then I can focus on other people rather than worrying about the impression that I am making. (Chandra, 53)

Because odor conveys meaning it both reflects character and expresses to others an awareness of and commitment to olfactory rules of decorum-precisely what Allison (age 32) suggested when she wrote, "smelling good gives the impression that I take care of myself and have consideration for others who have to spend time with me." Or, in other words, "just as the member of any group is expected to have self-respect, so also [s] he is expected to sustain a standard of considerateness" (Goffman 1967:10).

Olfactory impression management is imperative to the participants in this study and, all the more so, in situations they deem important. In these situations we see most clearly the kind of olfactory somatic work that "serves to counteract 'incidents' — that is, events whose effective 
symbolic implications threaten face" (Goffman 1967:12). Also in these situations people routinely engage in positive interpersonal rituals (Durkheim 1915, Goffman 1971:63)—rituals that "affirm and support the social relationship" between odors and their source. For example, Amy (age 31) explains why she was especially motivated to smell pleasant on her wedding day:

I was very conscious of wanting to smell good on my wedding day. Like every bride, I wanted to look beautiful and was afraid that I would get hot and sweaty in my big, heavy dress on a hot August day. I was aware that I would be hugged and kissed a lot on that day and that I would be talking to a lot of people (most of my closest family and friends, in fact) and for that reason was wanting to smell good.

Romantic encounters_-or circumstances where romance is possible-were also commonly cited as important moments for acute olfactory dramaturgical awareness and positive interpersonal olfactory ritual:

The greater the chance of intimacy the more important smelling good is. Walking the dog Saturday morning - don't care about my smell. Going to work - clean and fresh is good enough, no reason to break out the Baldessarini. Dancing, or any social situation where one is likely to get close to women, one wants to avoid being repugnant... (Peter, 57)

I like to smell good by applying perfume when I go out with my husband on a rare dinner date or to the movies (Allison, 32)

In addition to personal odor, the participants in this study were also dramaturgically aware of the significance of environmental olfactory impression management. Nearly all expressed concern about managing odor in places that people inhabit. Ashley (age 48) previously explained that the smell of a home reflects on its residents, and others expressed similar sentiments. As Jenna (age 33) wrote: A home must have controlled smells. No one wants to be in a home with offensive or too strong smells. No one would visit a smelly home and the occupants might 
carry the smells outside of the home with them making them unpleasant to be around (i.e. mold, cigarette smoke, crazy strong perfume).

Respondents also identified work environments as important places for the management of odor, and not only in terms of previously mentioned olfactory political correctness. Thus, it is not surprising that Susan (age 25) was especially dramaturgically aware of her olfactory impression management during important work-related meetings and interactions with clients:

It is particularly important for me to smell good when I am meeting clients-especially for the first time. Smell is such an important part of a person, whether you realize it or not, that a bad odour can break what could have been a great relationship! Before a meeting, I usually eat a mint, and wash my hands so I can be sure that I am presenting myself in the best way possible. Also, wearing clean clothes, bathing, and not going out the night before helps too!! ... I don't want to be remembered by a stench!

Restaurants were also identified as important environments for the control of odor. Kate (age 29) claims that "food is so tied with smells", Melissa (age 28) wrote "Smell definitely impacts the sense of taste", and therefore:

The sense of smell is being used to its fullest in a restaurant with all the culinary smells about. ...Good smells seem to enhance taste, and bad smells can just ruin the whole experience. Food establishments control smell also by putting familiar smells out to the public: popcorn at movies, fries from McDonald's (I've heard they fan it into the air outside). Smell is very important to sales I would imagine. (Melissa, 28)

The participants in this study cited bathrooms as among the most important environments for the control and manipulation of odor. Just as the smell of flatulence, urine, and feces contaminates the moral and aesthetic character of the olfactory offender, so too can it pollute an entire environment. As Cahill (1985:43) explains, "because the profaning power of odor operates 
over a distance and in all directions, moreover, individuals who defecate in...bathrooms not only temporarily profane themselves but also risk profaning the entire setting." However, because bathrooms are the designated place for "creature releases" (Goffman 1963a:69-9) —and all creatures must release - they are also social environments rife with negative interpersonal rituals (Durkheim 1915, Goffman 1971:62) that involve an honoring of the “individual's right to private 'preserves' and 'to be let alone"' (Cahill 1985:39). But adherence to this negative interpersonal ritual-especially in private bathrooms — entails a "dual set of issues for the offender and the offended" (Goffman 1971:100). On one hand, those who encounter the smells that emulate from a bathroom dutifully honor the negative ritual through "tactful blindness" (Goffman 1955:219). On the other hand, those who produce the smell are "responsible for trying to make amends for his [or her] offense and for showing proper regard for the process of correction" (Goffman 1971:100, emphasis in original). Therefore, as Nichole (age 40) suggests: "Like many people, I feel the need to remedy bathroom odours when they occur. Although everybody experiences and contributes to these odors, it seems important to hide them when they happen."

"In our society, defecation involves an individual in activity which is defined as inconsistent with the cleanliness and purity standards expressed in many of our performances"-writes Goffman (1959:121) — and even its smell is a possible expressive and impressive hazard. As numerous participants in this study suggest, failure to control the odors of flatulence, feces, and urine in the bathroom is a potential dramaturgical catastrophe-a source of looming prospective embarrassment, regardless of whether the bathroom is in a home, a work environment, for public or private use:

[It is important to control odor in] The bathroom: because it is a publicly used space and is often associated with negative smells resulting from bodily elimination. I leave a box of matches in the bathroom for guests or family members to light after using the toilet. I find 
the smell of burnt sulphur more appealing than artificial sprays. If odor is not controlled in these places then it may leave a bad impression for guests who visit our home. It is almost as if when a person uses the bathroom they want to feel as if they were the first and only ones to use it. It is unpleasant to be reminded that anyone visited the space before them (Allison, 32)

We found an especially incisive illustration of negative interpersonal olfactory rituals among our female respondents, who expressed a surprisingly recurring concern about their perception of body odor during menstruation. As Cindy (age 36) wrote, "Sometimes when on my menstrual cycle I think I smell bad and I feel quite worried at times, using perfume to cover it up." Cindy's use of perfume to cover, "pass” (Goffman 1963b), or otherwise distance herself from the perceived odor of her menstruating body is a clear example of negative olfactory interpersonal ritual. It also provocatively suggests the significance of moral and aesthetic assessments as they intersect with the politics of everyday life. "[B]ehind the myth of the perfumed sex, women are suspected of being naturally foul, reeking of unpleasant body fluids, such as menstrual blood” (Classen, Howes, and Synnott 1994:164):

I find that I am very self conscious about odour when I am on my period. I am just never sure if I smell "unfresh." It seems important for me to hide the fact that it is that time of the month. (Nichole, 40)

Indeed, an entire feminine hygiene industry is built on the dubious contention that women's bodies naturally stink and thus require potent remedies—remedies that are "necessary" and expected if women are to adhere to normative negative olfactory rituals. More generally, what is also implicit is a perceived odiferous abjection, which may be sanctioned by olfactory stigma. 


\section{Olfactory Stigma}

"I don't want to smell in public! I think it is humiliating to smell bad"—-vividly remarks Beth (age 31). She is not the only one in our sample who feels this way. As several participants in this study have suggested in their own words "particular odors, whether real or alleged, are sometimes used as indicants of the moral purity of particular individuals and groups within the social order, the consequences of which are indeed real" (Largey and Watson 1972:1022). In short, an odorous body is an offensive body (Hyde 2006) and failure to adhere to somatic rules and maintain expected olfactory impressions is potentially stigmatizing. Indeed, numerous participants in this study admit to judging people on the basis of their odor. And, as Susan (age 25) confesses, unpleasant odor results in olfactory stigma:

I find myself judging people negatively when they smell bad in some way — be it their breath, or something else. I don't usually notice if their smell is just normal or pleasant, but I definitely notice when it isn't.

Susan's sentiments might well explain why some people, like Amy (31, emphasis in original), are not so concerned about smelling fragrant but are quite concerned about the possibility of smelling awful: “While it's not necessarily important that I smell good I am very conscious of not wanting to smell bad."

It may be true that "smell is hardly ever considered as a political vehicle or a medium for the expression of class allegiances and struggles" (Classen, Howes, and Synnott 1994:161). Yet, for the participants in this study, class was commonly associated with olfaction. Odor is literally "classy" in that "smell provides a potent symbolic means for creating and enforcing class...boundaries" (Classen, Howes, and Synnott 1994:169):

The most offensive odour I recall is the odour unwashed people give off. It's not even really body odour-it's more of an all-encompassing, greasy, unclean smell. I associate this with 
the rough-looking (probably homeless) people I pass on the street. I actually find this odour more offensive than plain body odour. While not pleasant either, body odour is something I associate more with an occasional hygiene problem. This unwashed smell is worse because I associate it with a thoroughly unclean person. (Amy, 31)

Considering the significance of olfactory impression management and the potentially stigmatizing implications of odor, it is not surprising that the participants in this study vividly recall circumstances of somatic abjection — moments when they found themselves embarrassingly rank. Indeed, "the individual is always in jeopardy because of the adventitious linking of events, the vulnerability of his body, and the need in social situations to maintain the proprieties" (Goffman 1967:169); failure leads to embarrassment—a deficit in projecting an acceptable self before others (Goffman 1967; Gross and Stone 1964; Weinberg 1968; Weinberg and Williams 2005). Some of these recollections of olfactory abjection owe to accidental circumstances. For example, Frank (age 45) recalls falling into an abandoned latrine pit:

I remember a summer in Peachland when me and a couple of buddies were exploring an old abandoned campsite. ...I was not noticing where I was walking and stepped into an abandoned pit toilet. It took my two friends 20 minutes to get me out as they were laughing so hard as to make rescue that much more difficult. I stank really bad, as you may imagine, even after a "bath" in the lake. They made me ride in the stern of the boat on the way back to the cabin and I ended up showering at the camp site for $1 / 2$ an hour and burning my shorts.

However, the embarrassment of somatic abjection is easily "excused" (Scott and Lyman 1968) in accidental circumstances where one is "victimized" by the fickle hand of fate. More mortifying are moments of olfactory abjection that owe to one's own carelessness or inattentiveness. It is notable that many of these moments of olfactory abjection were merely perceived; people 
believed they stunk — no one necessarily shared that definition of the situation, and abjection (as well as its social consequence) was self-inscribed:

I was at work one day, and I had been out too late the night before. Not only did I not have time to shower, but I was convinced they could smell the beer on me from a mile away! Between that and the fact that I could not stop sweating-I was a TREAT to work with, I'm sure! I felt disgusting, and tried to avoid people the whole day. Even though my coworkers are in very close proximity to me, I sent them emails instead of talking to them face to face. I spent all day staring at my computer, trying not to wave my arms around or "waft" any of my smell in their general direction. I drank a lot of water, and washed my hands a lot to try and compensate for my stinkiness! I was SO glad to go home! I don’t know that anyone reacted to it, to be honest, but I kept thinking that people were shying away from me. I just felt so unprofessional and gross, that it ruined even my phone calls that day! (Susan, 25 emphasis in original).

It is difficult to tell if these memories of olfactory abjection were truly "discreditable" (Goffman 1963b:4). It is impossible to know if other people noticed the rank odor; as loyal citizens of expressive order those who smell the abject stench of another person may simply respond with polite "tactful blindness" (Goffman 1955:219). Indeed, tact is common and expected, but certainly not universal—some people are "discredited” (Goffman 1963b:4), and all olfactory abjection risks possible sanction:

One time I was trying on a wet suit in a diving store and it was a very hot day. I had just come from work and was wearing my work clothes. The wet suit I was trying on was extremely tight and it was really a lot of effort to get it on. I was sweating but what was worse was that my feet really smelled from the dress shoes that I was wearing. I needed the guy's help to get this wet suit on - he was very attractive and it was very embarrassing to ask 
for his help with such a horrible smell wafting through my dressing room. He said "what's that peculiar smell?" in a joking sort of way. I was mortified but stuck to the task at hand and got out of there quickly (Rose, 39).

Here too, as with the case of negative interpersonal olfactory rituals among women during menstruation, our data indicate an important gender dynamic. Women, much more commonly than men, report relatively frequent experiences with olfactory abjection and, once again, often in association with embodied experiences that are wholly feminine. For example, Allison (age 32) inexplicably despised the smell of her own body after child birth:

I hated the smell of myself after having a baby. During the weeks that followed my delivery I was followed by a distinct smell on my skin, hair and cloths that I had never smelled before. I can only explain it by pointing out the hormonal changes that were occurring in me at the time. I asked people around me if they could smell what I smelled but no one could. It only lasted about 3 weeks and then passed but I am curious to see if it occurs again with my second child. There wasn't much I could do about it because I was breastfeeding at the time and did not want to apply any fragrances to my skin that may interfere with my child's ability to feed well and establish physical closeness with me. I felt irritated and frustrated with the smell but hoped that it would pass, which it did.

While everyday life puts us all at risk of potential olfactory abjection, our data suggest the risk is greatest among women — and perhaps the stigmatizing consequences as well. Regardless, our data clearly suggest that women more vigilantly engage in active somatic surveillance which is, of course, a somatic social control. None of these gendered dynamics can be fully understood apart from the socio-cultural and, indeed, political structures of both sense-making and the somatic rules that structure them, in spite of evolutionary and pheromone accounts that seem intent to do so (see Stoddart 1990). 


\section{CONCLUSIONS}

"That which we call a rose by any other word would smell as sweet"—or so muses Juliet in Shakespeare's famous tragedy (Act II, Scene 2). However, not withstanding romance-in fact, quite to the contrary—our analysis suggests olfactory perception is not so simple. Olfactory perception hinges on active sense-making. Odor is made meaningful through denotative and connotative indexes, active reminiscing, the formulation of chains of associations, evaluation, interpretation, the significance of unique biographical particulars, the social norms of olfactory communities, and the indexical properties and qualities of odors themselves. Through smell, meaning is reflexively bestowed unto odor in the context of negotiated somatic rules. For this reason, odor is a "sign vehicle" (Goffman 1959) we thus manipulate and manage on bodies and in environments in an effort to convey desired impressions. Clearly, odor is a subtle but significant component of the culturally normative and aesthetic rituals of expressive and impressive everyday life.

"Smell is powerful" and yet, for the most part, "we breathe in the aromas which surround us without being consciously aware of their importance to us" (Classen, Howes, and Synnott 1994:1). Perhaps that explains the power of odor: olfactory perception seems so "natural," so unmitigated, such a raw, basic, and fundamental animal function. But this study suggests otherwise; the human animal defies such simplicities. We have empirically illustrated what Classen, Howes, and Synnott (1994:3, emphasis in original) conceptually argue_-“smell is cultural.” Yet, without pushing our social constructionist ontology too far we have highlighted how odors themselves are signs; indexes carrying unique odoriferous qualities, a true potential for meaning. The physiological nature of odors is, in fact, the raw materials of which olfactory perception is fashioned — and that fashioning is quintessentially cultural and natural at the same time. An object's meanings, including sensory perceptions, reside not in the object itself alone, but in the interaction or transaction of conduct directed toward it and the qualities emanating from it (Dewey 1958 [1934]; Mead 1934; also see 
Halton 2004; McCarthy 1984). In short, it is through forms of somatic work that sensory meaning is made. Indeed, as we suggested from the very beginning, people sense as well as make sense.

Goffman (1967:44-5, emphasis added) provocatively suggests that

If persons have a universal human nature, they themselves are not to be looked to for an explanation of it. One must look rather to the fact that societies everywhere, if they are to be societies, must mobilize their members as self-regulating participants in social encounters. One way of mobilizing the individual for this purpose is through ritual; he is tanght to be perceptive... it is these elements that are referred to in part when one speaks of universal human nature. Universal human nature is not a very human thing. By acquiring it, the person becomes a kind of construct, built up not from inner psychic propensities but from moral rules that are impressed upon him from without

The same may be said of the "common sense" of sense-making-olfactory or otherwise. Part of the seemingly universal "nature" of olfaction precisely owes to the fact that it is made "common sense" through ritual.

\section{NOTES}

1. Despite the relatively wide attention that odors and olfaction have received within psychology (e.g. Gilbert 1995; Stoddart 1990), related disciplines (e.g. Alaoui-Ismaili 1997; Vernet-Maury et al. 1999) and anthropology (e.g. Classen, Howes, and Synnott 1994; Stoller 1989; also see the interdisciplinary collection in Drobnick 2006), sociological attention to the matter has been scant (for notable exceptions see Largey and Watson 1972; Low 2005; Synnott 1991).

2. A useful way to conceptualize the idea of a group's somatic memory is through Maurice Halbwachs's (1992) notion of shared collective memory. 


\section{REFERENCES}

Alaoui-Ismaili, O., E. Vernet-Maury, A. Dittmar, G. Delhomme, and J. Chanel. 1997. "Odor Hedonics: Connection with Emotional Responses Estimated by autonomic Parameters.” Chemical Senses, 22:237-248.

Alaszewski, Andy. 2006. Using Diaries for Social Research. Thousand Oaks, CA: SAGE.

Barthes, Roland. 1974. S/Z. London: Cape.

Berger, Peter and Thomas Luckmann. 1966. The Social Construction of Reality. Garden City, N.Y.:

Doubleday.

Becker, Howard. 1963. Outsiders. New York: Free Press.

Brissett, Dennis and Charles Edgley. 1990. Life as Theater: A Dramaturgical Sourcebook. New York: Aldine.

Cahill, Spencer. 1985. “Meanwhile Backstage: Public Bathrooms and Interaction Order.” Urban Life 14:33-58,

Classen, Constance, David Howes, and Anthony Synnott 1994. Aroma: The Cultural History of Smell. New York: Routledge.

Corbin, Alain. 1986. The Foul and the Fragrant: Odor and the French Social Imagination. Boston: Harvard University Press.

Davis, Fred. 1979. Yearning for Yesterday: A Sociology of Nostlagia. New York: Free Press.

Dewey, John. 1934. Art as Experience. New York: Minton. 1967 [1887]. Psychology in John Dewey: The Early Works 1882-1898 volume 2 (edited by Herbert W. Schneider). Carbondale, IL: Southern Illinois University Press. . 2002 [1922]. Human Nature and Conduct. Amherst, N.Y.: Prometheus Books.

Douglas, Mary. 1970. Purity and Danger: An Analysis of Concepts of Pollution and Taboo. London: Harmondsworth. 
Drobnick, Jim. (Ed.) 2006. The Smell Culture Reader. New York: Berg.

Durkheim, Emile. 1915. The Elementary Forms of the Religious Life: A Study in Religious Sociology. New York: MacMillan.

Elias, Norbert. 2000. The Civiliqing Process. New York: Blackwell.

Fine, Gary A. 1995. "Wittgenstein's Kitchen: Sharing Meaning in Restaurant Work.” Theory and Society, 24:245-269.

Fine, Gary A and Tim Hallett. 2003. "Dust: A Study in Sociological Miniaturism.” The Sociological Quarterly. 44(1):1-15.

Gilbert, Avery. (Ed.) 1995. Compendium of Olfactory Research: Explorations in Aroma-Chology: Investigating the Sense of Smell and Human Response to Odors, 1982-1994. Dubuque, IO: Kendall/Hunt.

Goffman, Erving. 1955. "On Face-Work: An Analysis of Ritual Elements in Social Interaction.” Psychiatry: Interpersonal and Biological Processes, 18:213-231. . 1959. The Presentation of Self in Everyday Life. Garden City, NY: Doubleday. 1963. Stigma: Notes on the Management of Spoiled Identity. Englewood Cliffs, NJ: Prentice-Hall. . 1967. Interaction Ritual: Essays in Face-to-Face Behavior. Chicago: Aldine. . 1971. Strategic Interaction. Philadelphia: University of Pennsylvania Press.

Gross, Edward and Gregory P. Stone. 1964. "Embarrassment and the Analysis of Role Requirements." American Journal of Sociology, 70:1-15.

Halbwachs, Maurice. 1992. Maurice Halbwachs: On Collective Memory. Edited and Translated by Lewis Coser. Chicago: University of Chicago Press.

Halton, Eugene. 1986. Meaning and Modernity: Social Theory in the Pragmatic Attitude. Chicago: University of Chicago Press. . 2004. “The Living Gesture and the Signifying Moment.” Symbolic Interaction, 27:89-114. 
Herz, Rachel S. 2006. “I Know What I Like: Understanding Odor Preferences.” In Jim Drobnick (Ed.), The Smell Culture Reader. New York: Berg.

Hirsch, Alan. 2006. “Nostalgia: The Odours of Childhood and Society.” In Jim Drobnick (Ed.), The Smell Culture Reader. New York: Berg.

Hochschild, Arlie. 1983. The Managed Heart: Commercialization of Human Feeling. Berkeley, CA: University of California Press.

Hyde, Alan. 2006. “Offensive Bodies.” In Jim Drobnick (Ed.), The Smell Culture Reader. New York: Berg.

James, William. 1983 [1890]. Principles of Psychology. Boston: Harvard University Press.

Largey, Gale P. and David R. Watson. 1972. “The Sociology of Odours.” American Journal of Sociology, 77:1021-1034.

Low, Kelvin. 2005. "Ruminations on Smell as a Sociocultural Phenomenon.” Current Sociology. 53(3):397-417.

Mauss, Marcel. 1973 [1934]. “'Techniques of the Body.” Economy and Society, 2:70:87.

Mead, George H. 1938. The Philosophy of the Act. Chicago: University of Chicago Press.

Milligan, Melinda. 2003. “Displacement and Identity Continuity: The Role of Nostalgia in Establishing New Identity Categories.” Symbolic Interaction, 26:381-404.

Norton, T. 1975. Ordinal of Alchemy. Oxford: Oxford University Press

Peirce, Charles S. 1931. Collected Writings: Volumes 1-8. Cambridge, MA: Harvard University Press.

Proust, Marcel. 2001. In Search of Lost Time. New York: Random House.

Rapaport, Tamar, Edna Lomsky-Feder, and Angelika Heider. 2002. "Recollection and Relocation in Immigration: Russian-Jewish Immigrants 'Normalize' Their AntiSemitic Experiences." Symbolic Interaction. 25(2):175-98. 
Rochberg-Halton, Eugene. 1982. "Qualitative Immediacy and the Communicative Act." Qualitative Sociology, 5:162-181.

Rozin, Paul, Jonathan Haidt, and Clark McCauley. 1993. "Disgust.” Pp. 575-94 in Handbook of Emotions, edited by Michael Lewis and Jeannette Haviland. New York: The Guilford Press.

Scott, Marvin and Stanford Lyman. 1968. "Accounts." American Sociological Review, 33:42-62.

Simmel, Georg. 1997 [1907]. "Sociology of the Senses" in Simmel on Culture (edited by David Frisby and Mike Featherstone), pp. 109-120. Thousand Oaksm CA: Sage.

Snow, David and Leon Anderson. 1987. "Identity Work among the Homeless: The Verbal Construction and Awoval of Personal Identities.” American Journal of Sociology, 92:1336-1371.

Stoddart, David Michael. 1990. The Scented Ape: The Biology and Culture of Human Odour. London: Cambridge University Press.

Stoller, Paul. 1989. Taste of Ethnographic Things: The Senses in Anthropology. Philadelphia: University of Pennsylvania Press. 1997. Sensuous Scholarship. Philadelphia: University of Pennsylvania Press.

Synnott, Anthony. 1991. “A Sociology of Smell.” Canadian Review of Sociology and Anthropology, 28:437459. . 1993. The Body Social: Symbolism, Self, and Society. London: Routledge.

Summers, Montague. 1956. The History of Witchcraft and Demonology. New York: University Books.

Turner, Bryan. 2003. "Social Fluids: Metaphors and Meanings of Society.” Body and Society. 9:1-10.

Tuzin, Donald. 2006. "Base Notes: Odor, Breath, and Moral Contagion in Ilahita.” In Jim Drobnick (Ed.), The Smell Culture Reader. New York: Berg.

Vannini, Phillip. 2007. "Social Semiotics and Fieldwork: Method and Analytics." Qualitative Inquiry, $13: 113-140$. 
Vernet-Maury, E., O. Alaoui-Ismaili, A. Dittmar, G. Delhomme, and J. Chanel. 1999. "Basic Emotions Induced by Odorants: A New Approach Based on Autonomic Pattern Results.” Journal of Autonomous Nervous Systems, 75:176-183.

Volosinov, Valentin. 1973. Marxism and the Philosophy of Language. New York: Seminar Press.

Weinberg, Martin. 1968. "Embarrassment: Its Variable and Invariable Aspects.” Social Forces, 46:382388.

Weinberg, Martin and Colin Williams. 2005. "Fecal Matters: Habitus, Embodiments, and Deviance." Social Problems, 52:315-336.

Wiley, Norbert. 1994. The Semiotic Self. Chicago: University of Chicago Press.

Zerubavel, Eviatar. 1997. Social Mindscapes: An Invitation to Cognitive Sociology. Cambridge, MA: Harvard University Press. . 2006. The Elephant in the Room: Silence and Denial in Everyday Life. New York: Oxford University Press. 